Sociology and sport, the analysis of social grounds affecting the tendency of citizens toward the public sport in Iran:Case study: the city of Kerman in 2020

Alireza Sanatkhah*

\begin{abstract}
The present study has been done using the Survey Research. The research sample scale equals 400 people, besides its statistical population is included the 15-year population and most of the city of Kerman in 2020. The method of multistage-cluster-stratified sampling was used in five districts of the city of Kerman, moreover the results have been analyzed by SPSS and AMOSS16 software, and only is one model fitted with reality among five models of designed path. The results of analysis of path diagram indicate that other coefficients of the path all of them are significant except the direct impact of one's image of the body on sport-based cultural capital and social class on the tendency toward the public sport. Other results of the study suggest that sportbased socio-economic capital leaves an indirect effect on sport-based cultural capital by which the tendency of citizens toward the sport grows up. At that showing athletic advertisements in the media are effective on the tendency of citizens to public sport.
\end{abstract}

Key words: "cultural capital", "lifestyle", "management of the body", "public sport, "social capital"

\title{
Introduction and statement of the issue
}

Nowadays the process of the development of urban life and change of the daily motion patterns on account of reduction of motion activities have put organs and their muscles under the influence and serious danger of less mobility and physical weaknesses. It can be said that human are not able to show their initiative due to living in today's world and it undergoes human of movement deficiency; on the other the movement deficiency may cause numerous sociophysical-and-psychological problems. In this context, it seems, public sportas a strategic solution and the public sport as a cheap and hilarious means may properly solve this problem (Mumtāzbakhsh, 2007: 53) public sport may play a key role in many aspects of life especially the people of society's health regarding to its easiness of access and cheapness. (Țulūy $\bar{\imath}$ Ashlaq $\bar{\imath}$ et al., 2010)

${ }^{*}$ Assistant professor OF Department of Sociology, Kerman Branch, Islamic Azad University, Kerman, Iran (Corresponding Author) 
public sport is founded to increase the participation of all social groups, provide athletic duplication-oriented, and strengthen the championship sport, competitive sport, healthy recreations and recreational sport. (Rushandil, 2007) As one of the social phenomena in recent years, sport is considered as one of the most interesting subjects in the world. This phenomenon has had a welldeserved role in the lives of many people around the world in various socioeconomic-and-political aspects including human important activities. The popularity of sport has nearly increased and linked the sport and media up in

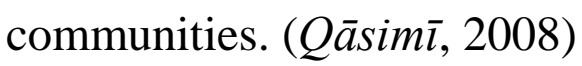

Public sport may deem as an organized and targeted game in which movements is going to enhance physical forces, increase morale, and acquire skills (Käshif 2000) besides the public sport comprises the age range of three to over septuagenarian that it encompasses different types of physical activities from non-regular and indigenous-spontaneous games to regular bodily exercises (Mumtāzbakhsh, 2007)

As we know, all people of society need to spend their leisure time appropriately and correctly, however, the youth, especially students, according to their critical and constructive role in the socio-cultural-and-economic construction of the country, in this regard, need to be paid more accurate attention (Lahsānizzädih et al., 2006) Today, spending the leisure time by sport is considered as an essential element in the lives of billions of people in the world. The present study is seeking to determine which factors (socio-economic-and-cultural) makes the citizens interpret the sport as a kind of lifestyle as well as a guide to prevent health problems, etc., furthermore they receive it as a means to achieve their own health to its supreme level.

\section{Literature review}

In the decades that have passed since the formation of the sociology of sport, knowing factors affecting participation in physical activity has been one of the most challenging issues of sociology of sport. (Saltz et al., 1987: 34)

Rossel\&Weingartner(2015: 43-59) in his review believes that Sociology of culture has established knowledge about the social processes in the production, valuation and consumption of cultural objects and the arts. results show that the Swiss cantons exhibit strikingly different patterns of cultural expenditure. Consistent with our main assumption, they are shaped by social, political and economic-geographic variables. Yet, the interplay of these variables differs between classical cultural expenditures and public funding of sports and leisure. Seifried \& Clopton(2013: 49-55) in his revew belives that According to this conception of social anchor theory, organizations and/or institutions can contribute to the development of the overall community through two 
components: social capital and collective identity. conclusions suggest that sport facilities are, indeed, viable social anchors within communities and community networks. Further, they are capable of maintaining a collective image or creating a preferred image for both community members and a fan nation. Finally, based on this information, municipal investment into sport venues should not be strictly looked at as a vehicle to produce economic returns.

Weiss in his review believes that factors such as health and safeness, improve the body's ability to learn new skills, build friendship relations, accept into peer groups, support by others who are important, enjoy due to a positive contribution and least negative experience associated with physical activity are effective on the tendency toward sport and sporting activities (Weiss, 1993; quoted by Hayani and Israel, 1996) On the other hand Hayani and Israel believes that the role of social support on behaviors related to health (i.e. physical activity) is effective. (Hayani and Israel, 1996: 26) Other researches accentuate the role of parents and peers on health-related behaviors; the most important researches may be pointed out to (Anderson et al., 1992), (Coakley, 1992) and (Ackers, 1992). In these studies, parents and peers may reinforce a person's desire for public sportand sport and clearly have an effect on individual's participation in the sport. Williamson et al. (1992) and Snyder and Spreitzer (1983) believe that family members' support, the spouse and friends' support play an important role in the sporting participation. (Quoted by Ayers, 1997: 67) For some researchers, socio-communicational networks (the number of individuals' calls with each other makes participation in bodily activities increased. (Hayani and Israel, 1996: 33) In other studies, in addition to the role of family and peers, the role of teachers, professors and media on participation in sporting activities is accented. (Bandura, 1997: 44) The support of family and friends is constantly effective on the level of individuals' participation in bodily activity. Moreover there are other results that express: People of the lower classes tend to exercises of the least expense, whereas those of the upper classes are desirous of costly exercises. (Coakley, 1998: 366) On the other hand, due to commercialization of sport, those who involved in professional sports invest in sport in those of the lower classes and exploit them of earning huge profits. These researchers argue that if it is supposed that the public sportdoes not become a class phenomenon, athletic facilities should be by a means available for those of middle and lower classes of society by non-profit institutions. (Foley, 1990) Those who assert the social aspects of sport (Foley, 1990) bring forth the issue of socialization and try to show that socialization through sport is an active process of learning and social development which is achieved as the result of interaction with others in the world of sport. Some studies have 
emphasized on cultural aspects of sport (Horn, 1999 quoted by Hawson, 2007: 24).Humberstone(2009: 255-262) focuses mainly on a the author's current experience of Higher Education and of a module concerned with gender, difference, sport and leisure made available to students studying for sport and leisure management degrees. It reviews the changed nature of the curriculum in the shifting socio-economic climate, suggesting that the neo-liberall turn influencing Higher Education in UK is reinforcing an organisational (university) culture which is counter productive to fostering critical gender and race awareness in both staff and students within restructured sport management programs.

\section{Theoretical framework of research}

No one may turn a blind eye on the efficacy of social relations and ties on the sport and how these relations and ties make the sport meaningful and interpret and justify it as a human activity (Anwar al-Khūli, 58: 2004) thus public sportmay not be far from the social thought governing a society that has embraced it. In order to determine the factors affecting the promotion of citizens' tendency toward the public sport, it is essential to consider the concept titled "lifestyle". According to this concept, answering these questions is obligatory that what factors make the diet and public sportfind a place in the lives of citizens? And people prefer prioritizing the sport and bodily activities in lieu of using things that are harmful to their health (including failure to comply with the diet, and smoking cigarette and hookah, drug abuse, etc.)? Above all, what factors make people set their life based on the sport-centered lifestyle? The concept of sport-oriented lifestyle, according to our desired definition, distances from the professional sport and refers to methods that citizens tend to the public sportand the sport for all to maintain their health. The sport in this definition is not considered as a profession, yet it is raised as a need and necessity of life to strengthen citizens' health.

At that, people choose their lifestyle to interact with each other and in an interpretative approach of situations. According to Goffman's view, there is a distance between "social self" and or "social identity" with "true self". (Quoted by $F \bar{a} t i h \bar{l}$ and Ikhlāși, 2008$)$ people while interacting attempt to show an aspect of self which is acceptable by others.

Others may judge about one's body fitness and management of the self-body as well. They may also judge on how much the health, diet and fitness is important to the individual. These judgments may be brought up by others with having expectations about one's correct management of the body. On the other hand, according to Giddens' view, it may be stated that these judgments and 
expectations is applied in a more effective way for citizens in different societies on the course of communities' evolution and by joining societies to the process of globalization. Because globalization in addition to having impact on economy, politics and social relations, it has also major influences on opinions, beliefs and in general the culture of people. Whether we like it or not, information waves would trek our borders by the help of technology getting more advanced every day. This knowledge and data would pave the way for needs that may be manifested in the direction of individuals' correct management of their bodies too. The method of people of developed countries and their advertisements toward body fitness and public sportin the form of movies, TV series and more generally through mass media would also penetrate in developing countries, and at first those of upper strata of the society in this regard will be made aware of and a kind of sensitivity is raised among them, then the said process will come down to people of lower ones. Nevertheless the formation of exercise-oriented lifestyle is also under the influence of socioeconomic conditions and circumstances, the pressures of group, the one's behavioral models. (Cockerham 2007: 163)

Citizens while interacting with others may learn the public sportas a key component to maintain health and fitness and choose their lifestyle based on a sport-centered one. In this context, the structure of social relations and ties plays a critical role. Opportunities at one's disposal may make socio-economiccultural capitals toward choosing a sport-oriented lifestyle in one based on Pierre Bourdieu's approach. (Bourdieu, 2002: 24, quoted by Amīrī Muqadam, 2008) Thus it is able to be admitted that citizens may select a healthy life by obtaining exercise-based socio-economic-cultural capitals for themselves.

\section{Hypotheses of research}

- There is a significant relationship between the marital status and tendency of citizens toward the sport for all. The coefficient of Chi-square $\left(\chi^{2}\right)$ equals to 152.782 which is significant with ( $\operatorname{sig}=0 / 000)$.

- There is a significant relationship between members of family and tendency of citizens toward the public sport. The coefficient of $\chi^{2}$ equals to 0.389 which is significant with ( $\operatorname{sig}=0 / 000)$.

- There is a significant relationship between the socio-economic stratum and tendency of citizens toward the public sport .The coefficient of Pearson equals to 0.141 which is significant with $(\mathrm{sig}=0 / 005)$. 
- There is a significant relationship between one's imagine of the body and tendency of citizens toward the public sport .The coefficient of Pearson at the (sig $=0.003)$ level equals to 0.150 and significant.

- There is a significant relationship between the media consumption and tendency of citizens toward the public sport. The coefficient of Pearson equals to 0.241 which is significant with ( $\mathrm{sig}=0 / 000$ ).

- There is a significant relationship between announcing athletic advertisements in the media and tendency of citizens toward the public sport. The coefficient of $\chi^{2}$ equals to 0.169 which is significant with ( $\mathrm{sig}=0 / 001$ ).

- There is a significant relationship between showing self-management of the body in the media and tendency of citizens toward the public sport. The coefficient of Pearson equals to 0.149 which is significant with ( $\operatorname{sig}=0 / 003$ ).

- There is a significant relationship between the exercise-based social capital and tendency of citizens toward the public sport .The coefficient of Pearson equals to 0.102 which is significant with ( $\mathrm{sig}=0 / 043$ ).

- There is a significant relationship between the exercise-based cultural capital and tendency of citizens toward the public sport The coefficient of Pearson equals to 0.174 which is significant with ( $\mathrm{sig}=0 / 001)$.

- There is a significant relationship between the exercise-based economic capital and tendency of citizens toward the public sport. The coefficient of Pearson equals to 0.392 which is significant with $(\mathrm{sig}=0 / 000)$.

\section{Methodology of research}

The present study was developed based on the survey method. The sample size of the study is estimated about 400-people based on Cochran formula. Combination of sampling methods of stratified-cluster based on sex and age was used to do the study in municipal zones of the city of Kerman. The statistical population equal to the total population of the city of Kerman in 2020 (i.e. approximately equals to 496684 persons). The validity of study is the construct one and as a means of measuring the reliability the Cronbach's $\alpha$ (alpha) coefficient is used. Cronbach's $\alpha$ coefficient has been reported for: (0.865) of the socio-economic stratum, (0.912) of one's understanding of the benefits of exercise, (0.859) of the importance of diet, (0.738) of sport-oriented economic capital, (0.736) of the tendency to public sport, (0.884) of broadcasting athletic ads in the media, (0.884) of the importance of fitness, (0.949) of the sport-based social capital, (0.829) of the exercise-centered cultural capital, (0.601) of media consumption and (0.937) of showing self- 
management of the body in the media. Nonetheless as for the conceptual definition of some variables of the study, it should be noted that:

Sport-oriented social capital accompanies with social frameworks in one (such as age, sex, marital status, etc.), as well as in family, friends, co-workers and other people close to the person that by them the interest and enthusiasm in one is raised to the correct management of the body and the tendency toward the sport. As a matter of fact, this type of capital points out to components in one's life that those are his incentive to choose a sport-based lifestyle. Doing athletic activities in the sports-oriented lifestyle is a need for the individual. It requires him to perform public sportduring the day. The more encouragement for the one's doing athletic movements are made by family, friends and colleagues, and at that the more facilities for doing athletic activities are provided by state institutions, the more suitable bed will be available for this type of capital. Furthermore exercise-based cultural capital refers to the cultural frameworks that through mass media (including satellite, Internet, TV, etc.) stimulates one's interest and enthusiasm to manage the body in a proper way and increases his tendency toward the sport. On the other hand the sports-oriented economic capital refers to the economic frameworks that provide an opportunity for the one so that he may be able to spend some time exercising during the day. Issues such as job responsibilities and overall income status, social class and the same as these issues may be named.

Table 1: study variables and some operational definitions

\begin{tabular}{|l|l|}
\hline \multicolumn{1}{|c|}{ Variables } & \multicolumn{1}{c|}{ Conceptual and operational definitions } \\
\hline Socio-economic class & $\begin{array}{l}\text { An objective definition of class is used to determine } \\
\text { the socio-economic class, the level of education, } \\
\text { cost of car, mobile price, residential house and other } \\
\text { properties }\end{array}$ \\
\hline One's image of the body & $\begin{array}{l}\text { That how much one thinks that if he attaches } \\
\text { importance to his health, diet and fitness, he looks } \\
\text { better in the eyes of others and others will respect } \\
\text { him more. }\end{array}$ \\
\hline Media consumption & Referring to how much one uses mass media. \\
\hline
\end{tabular}




\begin{tabular}{|l|l|}
\hline Broadcasting athletic ads in media & $\begin{array}{l}\text { Referring to the various athletic advertising that by } \\
\text { them citizens are encouraged to exercise. }\end{array}$ \\
\hline $\begin{array}{l}\text { Showing self-managements of the } \\
\text { body in media }\end{array}$ & $\begin{array}{l}\text { Watching sporting activity of film characters, for } \\
\text { instance, showing their sporting activity in the clubs, } \\
\text { paying attention to their going on a diet in movies, } \\
\text { TV series and things like that. }\end{array}$ \\
\hline $\begin{array}{l}\text { One's understanding of the benefits } \\
\text { of sporting activity }\end{array}$ & $\begin{array}{l}\text { One's knowledge about the efficacy of exercise on } \\
\text { reduction of blood pressure, cholesterol, blood } \\
\text { sugar, stress, and the effect of public sporton the } \\
\text { prevention of cardiovascular diseases, anxiety and } \\
\text { depression }\end{array}$ \\
\hline $\begin{array}{l}\text { Citizens' tendency toward the sport } \\
\text { for all }\end{array}$ & $\begin{array}{l}\text { Sporting activity at home (calisthenics, using } \\
\text { sporting equipment, etc.) sporting activity when } \\
\text { going to parks and other recreational areas, } \\
\text { mountain climbing, swimming, going to sport clubs, } \\
\text { walking regularly during the day }\end{array}$ \\
\hline
\end{tabular}

\section{Data analysis}

The population sample of research have been comprised by 191(48.7\%) people of females and $201(51.3 \%)$ of males. The mean age of individuals has been 1531 years among which $45.5 \%$ of singles, $51.1 \%$ of married and $3.5 \%$ of divorced people. About the structural path model, factors affecting the tendency of citizens toward the public sport, the coefficient of CMIN or the level of significance $(\mathrm{P}=0.124)$ equal to 25.037 has been reported that indicates there is not any significant difference between the experimental data and theoretical model. Other fit coefficients in Table 2 suggest a desirable fit.

Figure 1: Social factors influencing the citizens' tendency toward the public sport 


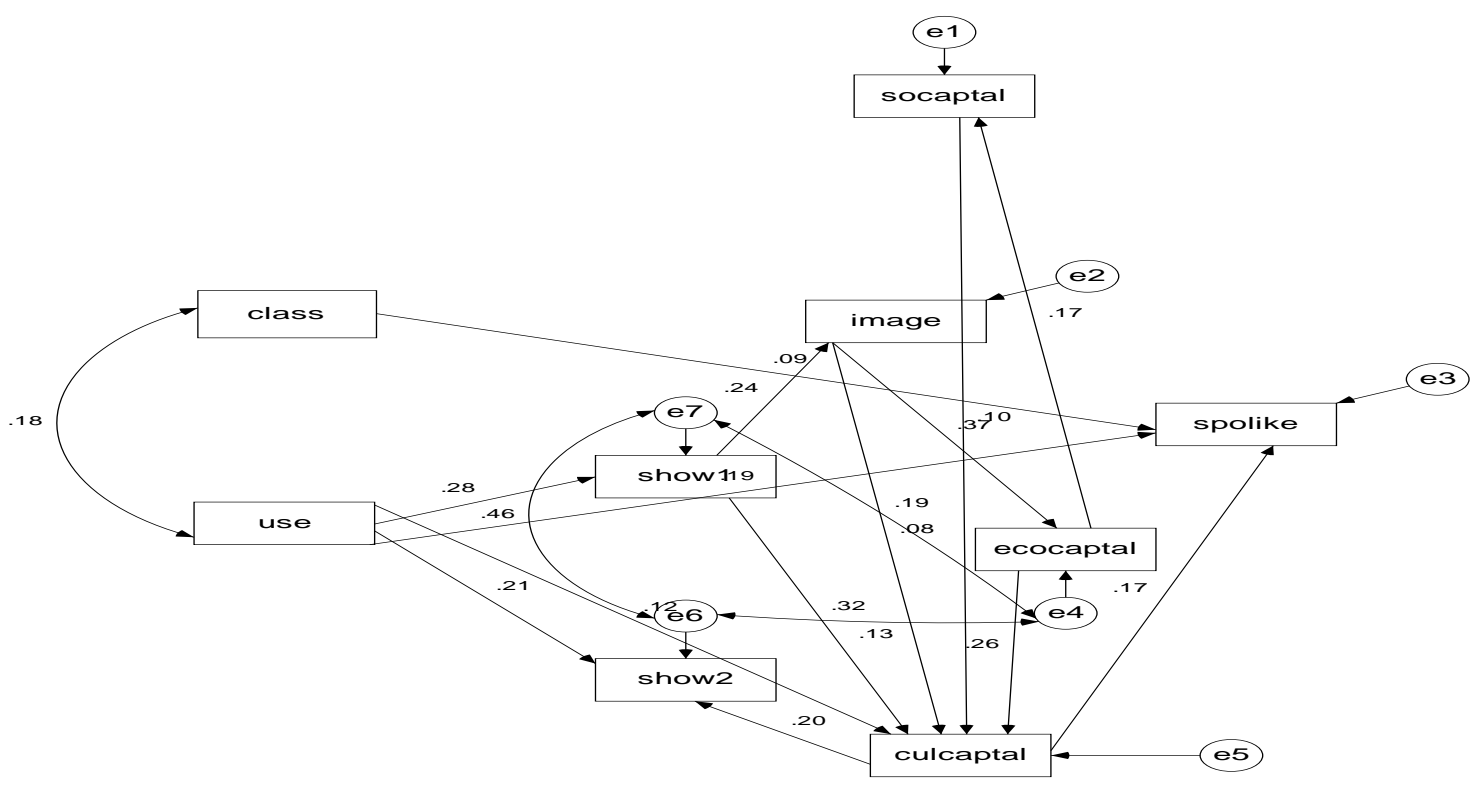

Class, socio-economic stratum; Image, one's image of the body; impor.1, the importance of diet; use, the media consumption; show1, broadcasting athletic ads in the media; show2, showing self-management of the body; understand, one's awareness of the benefits of sporting activity; Ecocaptal, the sport-oriented economic capital; Culcaptal, the exercise-based cultural capital; Socaptal, the sport-based social capital; Spolike tendency toward the public sport

Table 2: A summary report of fit coefficients of the structural model

\begin{tabular}{|c|c|c|c|c|}
\hline $\begin{array}{l}\text { Criterion of model } \\
\text { fitting }\end{array}$ & $\begin{array}{l}\text { Obtained rate } \\
\text { in the assumed } \\
\text { model }\end{array}$ & Acceptable level & Interpretation & $\begin{array}{l}\text { Acceptance } \\
\text { status }\end{array}$ \\
\hline GFI & 0.968 & $\begin{array}{l}0 \text { lack of fitting to } 1 \\
\text { complete fitting }\end{array}$ & $\begin{array}{l}\text { A rate close to } 0.59 \text { is } \\
\text { desirable fitting }\end{array}$ & Acceptable \\
\hline AGFI & 0.956 & $\begin{array}{l}0 \text { lack of fitting to } 1 \\
\text { complete fitting }\end{array}$ & $\begin{array}{l}\text { A rate close to } 0.59 \text { is } \\
\text { desirable fitting }\end{array}$ & Acceptable \\
\hline RMSEA & 0.032 & Less than 0.8 & Less than 0.8 is desirable & Acceptable \\
\hline TLI & .998 & $\begin{array}{l}0 \text { lack of fitting to } 1 \\
\text { complete fitting }\end{array}$ & $\begin{array}{l}\text { A rate close to } 0.59 \text { is } \\
\text { desirable fitting }\end{array}$ & Acceptable \\
\hline NFI & .996 & $\begin{array}{l}0 \text { lack of fitting to } 1 \\
\text { complete fitting }\end{array}$ & $\begin{array}{l}\text { A rate close to } 0.59 \text { is } \\
\text { desirable fitting }\end{array}$ & Acceptable \\
\hline PCFI & 0.394 & Higher than 0.05 or 0.06 & Higher than 0.05 or 0.06 & Acceptable \\
\hline
\end{tabular}


Table 3 shows the coefficients of standard and non-standard variables of the study. As it is conspicuous, other path coefficients, all of them, are significant apart from the direct impact of one's image of the body on the exercise-based cultural capital and social class on the tendency toward the public sport. The results suggest that the exercise-oriented social capital and the exercise-oriented economic capital by their indirect effect on the exercise-oriented cultural capital have an influence on citizens' tendency toward the public sport .At that showing sporting ads in the media the same way is effective on the tendency of citizens toward the public sport. Direct and indirect effects of other variables are clear in the path diagram. Corrects provided have been done mostly on the correlation of error variables (shown by e).

Table 3: The estimation of Standard and non-standard regression coefficients of variables of the research

$\begin{array}{llcccc} & & \begin{array}{c}\text { Regression } \\ \text { Weights }\end{array} & \text { S.E. C.R. } & \begin{array}{c}\text { Standardized } \\ \text { P Regression } \\ \text { Weights }\end{array} \\ \text { show1 <--- use } & .810 & .1405 .796 * * * & .277 \\ \text { image <--- show1 } & .226 & .0464 .960 * * * & .244 \\ \text { ecocaptal <--- image } & .167 & .0217 .870 * * * & .367 \\ \text { socaptal <--- ecocaptal } & 1.294 & .3853 .364 * * * & .168 \\ \text { culcaptal <--- image } & .065 & .0371 .758 .079 & .082 \\ \text { culcaptal }<---~ s o c a p t a l & .022 & .0102 .257 .024 & .097 \\ \text { culcaptal <--- show1 } & .233 & .0346 .910 * * * & .318 \\ \text { culcaptal <--- ecocaptal } & .451 & .0835 .457 * * * & .260 \\ \text { culcaptal <--- use } & .249 & .0942 .638 .008 & .116 \\ \text { show2 <--- use } & 1.075 & .2404 .483 * * * & .210 \\ \text { spolike } & <--- \text { culcaptal } & .049 & .0143 .530 * * * & .174 \\ \text { spolike } & <--- \text { class } & .029 & .0171 .773 .076 & .087 \\ \text { show2 <--- culcaptal } & .465 & .1144 .090 * * * & .195 \\ \text { spolike }<---~ u s e & .113 & .0303 .732 * * * & .187\end{array}$

Table 4: Covariance estimation between variables of the research 


$\begin{array}{rrrrrrr} & & & \text { Estimate } & \text { S.E. } & \text { C.R. } & \text { P } \\ \text { use } & <--> & \text { class } & 4.536 & 1.311 & 3.461 & * * * \\ \text { e4 } & <--> & \text { e7 } & 8.815 & 2.402 & 3.670 & * * * \\ \text { e6 } & <-> & \text { e7 } & 86.225 & 11.146 & 7.736 & * * * \\ \text { e6 } & <-> & \text { e4 } & 9.575 & 4.059 & 2.359 & .018\end{array}$

\section{Conclusion}

The aim of the study is to analyze sociological factors affecting tendency of citizens toward the public sport. The sample population of study has comprised 191 of females (48.7\%) and 201 of males $(51.3 \% 1)$. The average age was between $15-31$ that has formed $45.5 \%$ of singles, $51.1 \%$ of married and $3.5 \%$ of divorced people. The results of descriptive data showed that people in Kerman believe that the more diet on prepared foods, also the less consumption of food, the better manifestation in the eyes of others. The mean of responses obtained is higher than the average reported. At that the necessity of body fitness is of higher average of most responses given among citizens. Participating in body building clubs is of the furthest mean of responses, and then daily walking is of much tendency among citizens. Despite the positive assessment of citizens about the importance of diet and fitness, Data from the measurement of the tendency of citizens to public sport showed that the tendency of citizens toward doing athletic activities is much lower than the average. The results obtained of Path Model suggest that there is a transactional relationship between socioclass-and-media consumption. So that the upper classes have an access to a wider range of media that these interaction effects play an important role in the tendency toward the public sport; at that the results show that the higher classes have more leisure time which can be spent on various activities. These activities may include watching television, using other audio-visual media, doing sport activities at home with electric or non-electric sports facilities, or in clubs wellequipped. Socio-class relates to the public sport through a covariance associated with media consumption, however, the direct relation of this variable is not significant with the tendency toward the public sport. On the other hand media consumption impacts on variables such as announcing athletic promotions in 
media and showing self-management of the body which has an indirect effect on the tendency toward the public sport via broadcasting athletic advertisements. Nevertheless the relationship between self-management of the body and tendency toward the sport has not been reported significant; apart from this, announcing athletic advertisements in media in addition to the direct impact on the tendency toward the public sport, it is effective in the trends toward the public sport through indirect impacts by the one's imagination of the body and sport-oriented economic capital and sport-oriented cultural capital as well.

In the theoretical framework of research, it is has been noted that tends to public sport is formed based on social relations ruling on the community. This tendency is generated when the concept of sport-oriented lifestyle is formed in governing relations, and on the other hand this life style is itself made under the influence of interactional action of citizens with each other and according to Goffman's view in the process of formation of "self" of this trend and manifested based on the concept of "management of effectiveness". Others may also judge him about fitness and self-management of the body. Accordingly, variables of the one's imagination of the body have formed in the structural model. From Giddens point of view, these judgments are manifested in the form of convergence between countries on the course of social developments and the process of modernization process, and the convergence is intensified by globalization, meanwhile in this process the media's role is more prominent. As noted the media consumption relates to the social class. If the amount of athletic promotions and programs that somehow advertise sport-based culture increases, it will boost the citizens' trend toward the public sport according as the results of the study.

Nonetheless other components considered in the theoretical framework that can play a crucial role in tendency to public sport are sport-centered social, economic and cultural capitals. These three concepts have been formed and formulated based on Bourdieu theory. Still the direct relationship of sportoriented cultural capital and the tendency toward the public sport have been only confirmed in this study, two other types of sport-based socio-economic capital have the influence on the tendency toward the public sport through the impact on the sport-based cultural capital.

Sport-based cultural capital, as noted, refers to cultural frameworks that via mass media it creates enthusiasm and interest in one to manage his body correctly and makes the tendency to the sport. In this sense it is clear that the media has a very sensitive role. Furthermore advertising apropos of introducing 
the athletic venues, athletic equipment, etc. may increase the tendency toward the sport to a large degree.

References

1. Akers, r.l. (1985). Deviant behavior:a social learning approach, 3redn. Wadsworth, Belmont, ca. 67- 68.

2. Amīrī Muqadam, Marjān (2008). Sifting socio-cultural- and-economic factors effecting on ladies' trend of 18-40 years old of the city of Kerman toward sports. MA thesis in socio-sciences research of Islamic Azad University Roudehen Branch, pp. $18-64$

3. Anderssen, n.wold, B. (1992). Parental and peer influences on leisure- time physical activity in youny adolescents. Research quavterly for exerciseund sport. 63: 341- 348

4. Anwar al-Khūīī, Amin (2004). Sport and society. Translated by Ḥamīd Riḍā Shiykhī, Tehran: Samt Publications, pp. 1-80

5. Bandura, a. (1997) social learning theory. Prentice- hall enylewood cliffs, ni.,page 8

6. Coakley, j. white, a. (1992). Making decision: Gender and sport participation amony british adolescents. Sociology of sport journal. 9: 20- 35.

7. Cockerham,wiliam c(2007),social causes of health and disease,Cambridge:polity,page 1-14

8. Eyler, a. undetal. (1997). Physical activity and women in the united stutes: anover view of health benefits. Prevalence and intervention opportunities. Women and healt 26: 27- 150

9. Fātihī, Abulqāsim; Ikhlāṣī, Ibrahim (2008). Body management and its relationship with the social acceptance of the body. The case study of ladies of the city of Shiraz. Women Strategic Studies (Book of Women). Issue11. Fall, 1-18

10. Giddens, Anthony (2004), Modernity and Self-Identity; Self and society in the late modern age (Nāṣir Muvaffaqīyān). Tehran: Niy Press, 56-78

11. Heaney, c. a. Israel, b. a. (1996) social networks and social support. In k. glanz, f. m, lewis, b. k. riner,health behavior and health education theory, research and practice (pp: 179- 205). San francisso, ca: jossey- bass.

12. Howson, a \& Inglis , D(2007)," the body in sociolody: tensions inside inside 
and outside sociology: the editorial board of sociological review.

13. Humberstone,Barbara(2009) Sport management, gender and the 'bigger picture': Challenging changes in Higher Education-A partial auto/ethnographical account, Sport Management Review, Volume 12, Issue 4, November , Pages 255-262

14. Lahsānīzādih, 'Abdul' alī; Jahāngīrī, Jahāngīr; Tāmīyān, Ḥasan (2006). "Examining the factors influencing on students' interest in sport with a case study of students of University of Medical Sciences of Shiraz." Journal of humanities and social sciences of the University of Shiraz, 24 no. 2. Summer, 95-105

15. Mumtāzbakhsh, Maryam; Fakūr, Yūsuf (2007). "Viewing the strategies of development and promotion of sport for all of females of the University of Police Sciences." Quarterly of Police Knowledge, 9 no. 2. Summer, pp. 53-62.

16. Qāsimī, Vahīd (2008). "Capital and Structural determinants of lifestyle of healthoriented". Iran's social issues, 16 no. 63. Winter, pp. 181-213

17. Ritzer, George (1995). A survey of modern social theories. Translated by Muhsin Thalāthī, Tehran: 'Ilm Press, p. 296

18. Rossel,Jorg,Weingartner,Sebastian(2015) Nothing but the cuckoo clock? Determinants of public funding of culture in Switzerland, 1977-2010, Poetics, Volume 49, April , Pages 43-59

19. Rushandil Arbațānī, Tāhir (2007). "Explaining the place of mass media in the institutionalization of sport for all in the country". Journal of Harikat, 33 no. 33, March, 1-13

20.Sallis, J.F., Grossman, R.M., Pinski, R.B., Patterson, T.L., and Nader, P.R. (1987). The development of scales to measure social support for diet and exercise behaviors. Preventive Medicine, 16, .825-836

21. Sefried,Chad,Clopton,Aaron W.(2013) An alternative view of public subsidy and sport facilities through social anchor theory, City, Culture and Society, Volume 4, Issue 1, March, Pages 49-55

22. Țulūȳi Ashlaqī, "Abbās; Pāshāȳi, Maḥmūd (2007). "The role of mass media in the development of citizenship exercise (sport for all)." Urban Management Studies, 2 no. 2. Summer, pp. 181-192.

23. Vilhjalmsson, Runra. Thorlindsson Therdfar (1998). Factors related to physical activity: a study of a dolescents. Journal social and medicine.,page 78-110 